\title{
Co-occurring mental illness, drug use, and medical multimorbidity among lesbian, gay, and bisexual middle-aged and older adults in the United States: a nationally representative study
}

\author{
Benjamin H. $\operatorname{Han}^{1,2^{*}}$ (D), Dustin T. Duncan ${ }^{3}$, Mauricio Arcila-Mesa ${ }^{2}$ and Joseph J. Palamar ${ }^{1}$
}

\begin{abstract}
Background: Older lesbian, gay, and bisexual (LGB) adults are an underserved and understudied population that experience specific health disparities. The intersection of aging and chronic medical disease with a higher risk for substance use and mental illness may place older LGB adults at risk for co-occurring conditions and resulting comorbidity. Understanding multimorbidity among older LGB adults may help inform interventions to reduce disparities in health outcomes.
\end{abstract}

Methods: Data come from the 2015 to 2017 National Surveys on Drug Use and Health $(n=25,880)$. We first determined whether sexual orientation was associated with reporting: past-year drug use, mental illness, and/or 2 or more chronic medical diseases. We then determined whether sexual orientation was associated with reporting co-occurrence of these conditions. This was done using multivariable logistic regression. Analyses were stratified by gender.

Results: Compared to heterosexual men, gay men were at increased odds for reporting 2 or more chronic medical diseases (adjusted odds ratio $[\mathrm{aOR}]=2.18,95 \%$ confidence interval $[\mathrm{Cl}]=1.48,3.21)$, and gay $(\mathrm{aOR}=1.79,95 \% \mathrm{Cl}=1.09$, 2.93) and bisexual men $(\mathrm{aOR}=3.53,95 \% \mathrm{Cl}=2.03,6.14)$ were at increased odds for reporting mental illness. Gay men $(\mathrm{aOR}=2.95,95 \mathrm{Cl}=1.60,5.49)$ and bisexual men $(\mathrm{aOR}=2.84,95 \% \mathrm{Cl}=1.58,5.08)$ were at increased odds of reporting cooccurring conditions. Compared to heterosexual women, bisexual women were at increased odds for past-year drug use $(\mathrm{aOR}=4.20,95 \% \mathrm{Cl}=2.55,6.93)$, reporting mental illness $(\mathrm{aOR}=1.94,95 \% \mathrm{Cl}=1.03,3.67)$, and reporting co-occurring conditions ( $\mathrm{aOR}=3.25,95 \%=1.60,6.62)$.

Conclusions: Middle-aged and older LGB adults in the United States are at high risk for experiencing co-occurring drug use, mental illness, and/or medical multimorbidity. Interventions for older sexual minority populations are needed to reduce disparities.

Keywords: Chronic disease, Multimorbidity, Geriatrics, Sexual minorities

\footnotetext{
* Correspondence: Benjamin.Han@nyumc.org

'Department of Population Health, New York University School of Medicine, 550 First Avenue, New York, NY 10016, USA

${ }^{2}$ Division of Geriatric Medicine and Palliative Care, Department of Medicine, New York University School of Medicine, 550 First Avenue, New York, NY 10016, USA

Full list of author information is available at the end of the article
}

(c) The Author(s). 2020 Open Access This article is licensed under a Creative Commons Attribution 4.0 International License, which permits use, sharing, adaptation, distribution and reproduction in any medium or format, as long as you give appropriate credit to the original author(s) and the source, provide a link to the Creative Commons licence, and indicate if changes were made. The images or other third party material in this article are included in the article's Creative Commons licence, unless indicated otherwise in a credit line to the material. If material is not included in the article's Creative Commons licence and your intended use is not permitted by statutory regulation or exceeds the permitted use, you will need to obtain permission directly from the copyright holder. To view a copy of this licence, visit http://creativecommons.org/licenses/by/4.0/. The Creative Commons Public Domain Dedication waiver (http://creativecommons.org/publicdomain/zero/1.0/) applies to the data made available in this article, unless otherwise stated in a credit line to the data. 


\section{Background}

Existing research demonstrates sexual minority disparities in mental illness, drug use (including substance use disorders [SUDs]), chronic health conditions, and healthrelated behaviors among adults [1-6]. Awareness of the health burdens experienced by sexual minorities, including lesbian, gay, bisexual, and transgender (LGBT) adults has increased, with their inclusion in the US Department of Health and Human Services' Healthy People 2020 as an goal to improve the health of sexual minorities [7].

However, despite the aging of the US population, middle-aged and older LGBT adults remain an understudied group with notable gaps in aging research for this population [8]. An estimated $2 \%$ of the US population age $\geq 65$ identify as LGBT, and this population is likely to grow with a population increase of older adults and as more older adults may feel comfortable answering questions about sexual minority status and gender identity [9]. The health of middle-aged and older LGBT adults should be a priority as aging is the main risk factor for the presence of multiple chronic conditions, declines in physical and cognitive function, and increases in healthcare utilization [10]. One study examining data from the 2013-2014 National Health Interview Survey (NHIS) found that among adults age $\geq 50$ who identify as lesbian, gay, or bisexual (LGB), older lesbian or bisexual women were more likely to have more chronic diseases while older gay or bisexual men were more likely to have angina pectoris or cancer, and disability was higher among LGB older adults for both identities compared to older heterosexuals [3]. Other studies have shown higher rates of anxiety, depression, illicit opioid use, prescription tranquilizer misuse, and SUDs among middle-aged and older LGBT adults [9, 11, 12].

Conversely, another study from the 2013-2014 NHIS of adults age 65 and older found sexual minorities were more likely to report excellent or very good health compared to heterosexuals and found no significant difference in functional limitations or impairments [13]. However, a limitation is that many of these studies have small sample sizes or combine gay/lesbian with bisexual individuals into one category, and few research has examined the health of middle-aged and older LGBT adults through a multimorbidity framework.

Adults with medical multimorbidity, generally defined as $\geq 2$ concurrent chronic conditions, have high rates of healthcare utilization and often receive poorly coordinated care [14, 15]. Chronic medical diseases, mental illness, and substance use frequently are interrelated and represent a compound multimorbidity placing individuals at even higher risk for adverse outcomes including increases in healthcare utilization [16]. Given that previous research shows high rates for mental illness, drug use, and medical multimorbidity among older LGB adults $[3,9]$, the goal of this current study was to examine differences regarding these three elements as well as the prevalence of having 2 or 3 concomitant problems using data from a nationally representative sample. As the population of older sexual minorities increases $[9,17]$, the objective for this study is to better understand the complexity of LGB adults' health through a multimorbidity lens to help inform multidisciplinary clinical interventions in order to reduce health disparities in this population.

\section{Methods \\ Study population}

Aggregated data from the 2015-2017 National Survey on Drug Use and Health (NSDUH) were analyzed. NSDUH is an ongoing cross-sectional survey of noninstitutionalized individuals in the 50 US states and the District of Columbia [18]. Data are derived from nationally representative probability samples of populations living in households, noninstitutional group quarters, and shelters, obtained through four sampling stages. Surveys were administered via computer-assisted interviewing conducted by an interviewer and audio computer-assisted self-interviewing. Sample weights were provided by NSDUH to address unit- and individual-level nonresponse. Weights were adjusted to ensure that estimates were consistent with estimates provided by the US Census Bureau. Further details regarding sampling and survey methods can be found elsewhere [19]. The weighted interview response rates were 69.7\% (2015), 68.4\% (2016), and $67.1 \%$ (2017). This study focuses on adults age $\geq 50$ ( $n=$ 25,880).

\section{Study measures}

\section{Sexual orientation and sexual minority status}

Participants were asked, "Which one of the following do you consider yourself to be?" and answer options were "heterosexual, that is, straight," "lesbian or gay," and "bisexual." Participants could also report that they do not know or refuse to answer.

\section{Drug use}

Participants were asked about past-year use of various drugs. In these analyses, we considered past-year selfreported use of cannabis (among those reporting it was never recommended by a doctor), any other illegal drug use (i.e., cocaine, lysergic acid diethylamide [LSD], ecstasy, methamphetamine, ketamine, gamma hydroxybutyrate $[\mathrm{GHB}]$, phencyclidine $[\mathrm{PCP}], \mathrm{N}, \mathrm{N}$-dimethyltryptamine [DMT], heroin), and misuse of prescription pain-relievers (prescription opioids) and tranquilizers (e.g., benzodiazepines aside from flurazepam, temazepam, and triazolam; muscle relaxants). Misuse was defined as using without one's own prescription; using in greater amounts, more often, or for longer than directed; or use in any way not 
directed by a doctor. Participants were shown images of various opioid and tranquilizer pills to aid in their recall. We created a variable indicating past-year drug use, which included nonmedical cannabis use, illegal drug use, and prescription drug misuse to encompass the range of potentially unhealthy drug use (which could increase the risk for health consequences).

\section{Mental illness}

NSDUH includes an indicator for past-year mental illness developed and validated by the Substance Abuse and Mental Health Services Administration and the National Institute of Mental Health, which is based on responses to a list of questions asked by NSDUH. The items include level of emotional distress, functional impairment due to emotional distress, suicidal thoughts, and major depression. Based on the responses an individual is given a dichotomous (yes/no) value for mild, moderate, and severe mental illness. Our definition for mental illness included meeting criteria for moderate or severe mental illness, which is equivalent to Global Assessment of Functioning (GAF) scores of $<60$ (serious mental illness is GAF $<50$; moderate mental illness is $50 \leq \mathrm{GAF}<60)[20]$.

\section{Medical multimorbidity}

Participants were asked if they had ever had a doctor diagnose them with the following medical conditions: asthma, bronchitis/chronic obstructive pulmonary disease (COPD), cancer, cirrhosis, diabetes, heart conditions, hepatitis $\mathrm{B}$ or $\mathrm{C}$, high blood pressure, HIV/AIDS, and kidney disease. Similar to previous studies, we created a variable indicating medical disease multimorbidity which was defined as $\geq 2$ chronic conditions reported $[14,15]$.

\section{Composite of co-occurring conditions}

We created a variable indicating the total number of the three interrelated conditions: any past-year drug use, any past-year mental illness, and medical multimorbidity. The composite was coded into 0,1 , and $2-3$ conditions. Three conditions were combined with two conditions due to the low prevalence of those reporting all three outcomes.

\section{Covariates}

We included the following sociodemographic variables as covariates: age group (categorized by NSDUH as 50 $64, \geq 65$ ), gender, race/ethnicity, education, annual family income, marital status, and whether they receive government assistance.

\section{Statistical analysis}

Similar to other studies focused on sexual minorities, all analyses were stratified by gender [2, 3]. First, we compared socio-demographic characteristics as well as specific drug use, mental illness, and medical multimorbidity characteristics according to sexual minority status for descriptive purposes. Comparisons were made using Rao-Scott chi-square as this bivariable test takes into account for the complex survey design [21]. We then compared the cooccurring outcome composite variable by heterosexual, lesbian, gay, and bisexual adults in a similar manner. After examining bivariable associations we examined whether sexual minority status was related to reporting drug use, mental illness, and medical multimorbidity in a multivariable manner. Specifically, we examined whether sexual minority status was related to each outcome in three separate binary logistic regression models. Then, using multinomial logistic regression, we determined whether sexual minority status was related to reporting one condition, and 2-3 conditions, compared to reporting no conditions. Since only 413 participants reported "don't know" or "refuse" as a response for the sexual orientation item, these cases were excluded from the main analyses which focused on the 11,876 men and 14,004 women identifying as heterosexual, gay/lesbian, or bisexual. However, we also conducted a supplemental analysis in which we included those who reported "don't know" or "refuse" as a response in multivariable models (men $n=12,025$, female $n=14$, 268). All models controlled for all socio-demographic covariates described above. We used sampling weights (provided by NSDUH) to account for selection probability, non-response, and population distribution, and data were analyzed using survey "svy" commands in Stata SE 13 (StataCorp LP, College Station, TX) which allowed us to account for the complex survey design [21]. We used imputation-revised variables when available to limit missing data as specified and provided by NSDUH [19]. Secondary analysis of these data was exempt for review by our Institutional Review Board.

\section{Results}

Most (97.0\%) male participants identified as heterosexual, with $1.9 \%$ identifying as gay, and $1.1 \%$ identifying as bisexual. Similarly, $97.9 \%$ of women identified as heterosexual, $1.2 \%$ identified as lesbian, and $0.8 \%$ identified as bisexual. As is shown in Table 1, we estimate differences in demographics, drug use, mental illness, and chronic disease between older LGB respondents compared to their heterosexual counterparts stratified by gender. LGB individuals were younger with a higher percentage not married than heterosexuals. Gay men had the highest percentage with an earned a college degree. With regard to past-year drug use, bisexual women had the highest prevalence of nonmedical use of cannabis and misuse of 
Table 1 Sociodemographic, Drug Use, Mental IIIness, and Chronic Disease Characteristics by Sexual Orientation among Adults Age $\geq 50$, United States, 2015-2017

\begin{tabular}{|c|c|c|c|c|c|c|c|c|}
\hline & \multicolumn{4}{|l|}{ Men } & \multicolumn{4}{|l|}{ Women } \\
\hline & $\begin{array}{l}\text { Total } \\
(n=11,876) \\
\%(\mathrm{SE})\end{array}$ & $\begin{array}{l}\text { Hetero-sexual } \\
(n=11,509), \\
\%(\mathrm{SE})\end{array}$ & $\begin{array}{l}\text { Gay } \\
(n=227) \\
\%(\mathrm{SE})\end{array}$ & $\begin{array}{l}\text { Bisexual } \\
(n=140) \\
\%(\mathrm{SE})\end{array}$ & $\begin{array}{l}\text { Total }(n=14,004) \\
\%(\mathrm{SE})\end{array}$ & $\begin{array}{l}\text { Hetero-sexual } \\
(n=13,708) \\
\%(\mathrm{SE})\end{array}$ & $\begin{array}{l}\text { Lesbian } \\
(n=173) \\
\%(\mathrm{SE})\end{array}$ & $\begin{array}{l}\text { Bisexual } \\
(n=123) \\
\%(\mathrm{SE})\end{array}$ \\
\hline \multicolumn{9}{|l|}{ Survey Year } \\
\hline 2015 & $33.0(0.7)$ & $33.1(0.7)$ & $31.0(4.3)$ & $32.5(5.5)$ & $32.8(0.5)$ & $32.7(0.5)$ & $33.5(5.3)$ & $40.4(5.1)$ \\
\hline 2016 & $33.2(0.5)$ & $33.2(0.5)$ & $35.1(3.5)$ & $27.7(4.4)$ & $33.3(0.5)$ & $33.4(0.5)$ & $33.6(4.8)$ & $20.7(4.3)$ \\
\hline 2017 & $33.8(0.6)$ & $33.7(0.6)$ & $33.9(4.6)$ & $39.8(5.4)$ & $33.9(0.4)$ & $33.9(0.4)$ & $33.0(4.6)$ & $39.0(4.6)$ \\
\hline \multicolumn{9}{|l|}{ Age } \\
\hline $50-64, y$ & $58.4(0.5)^{b}$ & $58.1(0.5)$ & $75.0(3.3)$ & $62.1(5.6)$ & $54.8(0.5)^{b}$ & $54.5(0.6)$ & $66.2(5.5)$ & $76.3(4.8)$ \\
\hline$\geq 65, y$ & $41.6(0.5)$ & $41.9(0.6)$ & $25.0(3.3)$ & $37.9(5.6)$ & $45.2(0.5)$ & $45.5(0.6)$ & $33.8(5.5)$ & $23.7(4.8)$ \\
\hline \multicolumn{9}{|l|}{ Race/Ethnicity } \\
\hline White & $74.2(0.5)$ & $74.3(0.5)$ & $69.9(4.0)$ & $66.3(4.9)$ & $72.8(0.6)$ & $72.7(0.6)$ & $81.4(3.5)$ & $63.5(4.6)$ \\
\hline Black & $9.6(0.3)$ & $9.5(0.3)$ & $10.3(2.0)$ & $11.3(3.4)$ & $11.1(0.4)$ & $11.1(0.4)$ & $7.0(2.6)$ & $9.7(3.4)$ \\
\hline Hispanic & $10.4(0.4)$ & $10.3(0.4)$ & $14.8(3.3)$ & $10.5(4.0)$ & $10.1(0.4)$ & $10.1(0.4)$ & $6.8(2.2)$ & $16.0(4.1)$ \\
\hline Asian/Other & $5.9(0.3)$ & $5.9(0.3)$ & $5.1(2.6)$ & $11.8(4.1)$ & $6.1(0.3)$ & $6.0(0.3)$ & $4.8(2.0)$ & $10.8(3.9)$ \\
\hline \multicolumn{9}{|l|}{ Education } \\
\hline Less than High School & $13.7(0.4)^{c}$ & $13.8(0.4)$ & $9.8(2.1)$ & $11.2(2.9)$ & $13.8(0.4)^{c}$ & $13.8(0.4)$ & $11.3(2.9)$ & $18.4(3.5)$ \\
\hline High School Diploma & $26.4(0.5)$ & $26.8(0.5)$ & $11.6(2.5)$ & $17.4(4.0)$ & $27.1(0.5)$ & $27.4(0.5)$ & $11.2(2.9)$ & $16.4(3.8)$ \\
\hline Some College & $25.8(0.5)$ & $25.9(0.6)$ & $25.9(3.6)$ & $20.8(4.1)$ & $29.5(0.5)$ & $29.4(0.5)$ & $33.0(4.2)$ & $34.0(5.1)$ \\
\hline College Degree & $34.1(0.6)$ & $33.5(0.6)$ & $52.7(4.6)$ & $50.6(4.1)$ & $29.7(0.7)$ & $29.5(0.7)$ & $44.5(5.0)$ & $31.3(4.5)$ \\
\hline \multicolumn{9}{|l|}{ Annual Family Income } \\
\hline$<\$ 20,000$ & $13.2(0.4)^{a}$ & $13.0(0.4)$ & $15.8(2.5)$ & $25.9(4.9)$ & $17.8(0.5)$ & $17.8(0.5)$ & $18.5(4.2)$ & $18.5(4.8)$ \\
\hline$\$ 20,000-\$ 49,999$ & $28.0(0.5)$ & $28.0(0.5)$ & $28.3(4.0)$ & $28.6(4.7)$ & $31.9(0.5)$ & $31.9(0.5)$ & $28.9(4.0)$ & $36.0(5.6)$ \\
\hline$\$ 50,000-\$ 74,999$ & $17.0(0.4)$ & $17.0(0.5)$ & $21.5(3.9)$ & $13.2(3.6)$ & $16.4(0.3)$ & $16.4(0.4)$ & $19.4(3.2)$ & $16.2(4.1)$ \\
\hline$\geq \$ 75,000$ & $41.8(0.6)$ & $42.0(0.6)$ & $34.4(4.8)$ & $32.3(4.6)$ & $33.9(0.5)$ & $33.9(0.5)$ & $33.3(4.2)$ & $29.4(4.6)$ \\
\hline \multicolumn{9}{|l|}{ Relationship Status } \\
\hline Not Married & $30.7(0.5)^{c}$ & $29.6(0.4)$ & $75.4(3.4)$ & $59.0(5.2)$ & $44.4(0.6)^{c}$ & $44.0(0.6)$ & $63.9(5.6)$ & $64.2(4.3)$ \\
\hline Married & $69.3(0.5)$ & $70.4(0.4)$ & $24.6(3.4)$ & $41.0(5.2)$ & $55.6(0.6)$ & $56.0(0.6)$ & $36.1(5.6)$ & $35.8(4.3)$ \\
\hline Government Assistance & $13.7(0.4)$ & $13.6(0.4)$ & $18.2(3.5)$ & $15.5(3.2)$ & $17.5(0.4)$ & $17.4(0.4)$ & $21.2(4.1)$ & $25.2(4.3)$ \\
\hline \multicolumn{9}{|l|}{ Past-Year Drug Use } \\
\hline Any Past-Year Drug Use & $10.5(0.3)^{c}$ & $10.2(0.3)$ & $20.9(4.6)$ & $20.4(4.7)$ & $6.7(0.2)^{c}$ & $6.5(0.2)$ & $13.1(2.9)$ & $27.7(4.4)$ \\
\hline Cannabis (unprescribed) & $7.4(0.3)^{a}$ & $7.2(0.3)$ & $13.4(4.1)$ & $14.4(3.8)$ & $4.1(0.2)^{c}$ & $3.9(0.2)$ & $9.2(3.0)$ & $21.2(4.1)$ \\
\hline Opioids (misuse) & $2.8(0.2)^{a}$ & $2.7(0.2)$ & $5.6(1.9)$ & $5.3(1.7)$ & $2.1(0.1)^{b}$ & $2.0(0.1)$ & $1.8(1.1)$ & $6.6(2.2)$ \\
\hline Tranquilizers (misuse) & $1.2(0.1)^{c}$ & $1.1(0.1)$ & $5.4(2.0)$ & $4.2(2.1)$ & $1.1(0.1)$ & $1.1(0.1)$ & $2.1(1.4)$ & $1.7(1.2)$ \\
\hline Illegal Drugs (non-cannabis) & $1.5(0.1)^{a}$ & $1.5(0.1)$ & $2.7(1.4)$ & $4.8(2.0)$ & $0.7(0.1)^{b}$ & $0.7(0.1)$ & $0.8(0.8)$ & $4.1(2.3)$ \\
\hline \multicolumn{9}{|l|}{ Mental Illness (Past Year) } \\
\hline Mental illness $^{d}$ & $4.8(0.2)^{c}$ & $4.5(0.2)$ & $9.8(2.4)$ & $16.8(3.4)$ & $7.9(0.3)^{b}$ & $7.8(0.3)$ & $8.7(2.6)$ & $17.8(4.3)$ \\
\hline \multicolumn{9}{|l|}{ Chronic Disease } \\
\hline Asthma & $5.8(0.3)$ & $5.7(0.3)$ & $8.7(2.3)$ & $6.3(2.8)$ & $9.8(0.3)$ & $9.7(0.3)$ & $15.0(3.3)$ & $13.1(3.7)$ \\
\hline Bronchitis/COPD & $6.0(0.3)$ & $6.0(0.3)$ & $8.2(1.9)$ & $8.6(2.5)$ & $9.0(0.3)^{a}$ & $8.9(0.3)$ & $15.6(3.9)$ & $12.0(3.4)$ \\
\hline Cancer & $10.7(0.4)$ & $10.7(0.4)$ & $12.6(3.1)$ & $8.1(2.4)$ & $12.5(0.3)$ & $12.5(0.4)$ & $13.2(3.5)$ & $13.9(3.9)$ \\
\hline Cirrhosis & $0.7(0.1)$ & $0.7(0.1)$ & $0.8(0.8)$ & $0.0(0.0)$ & $0.4(0.1)$ & $0.4(0.1)$ & $0.0(0.0)$ & $2.0(1.4)$ \\
\hline Diabetes & $18.4(0.5)$ & $18.4(0.5)$ & $19.8(3.3)$ & $13.5(3.0)$ & $16.8(0.4)$ & $16.9(0.4)$ & $18.2(3.4)$ & 10.9 (2.6) \\
\hline Heart Condition & $22.1(0.6)$ & $22.1(0.5)$ & $22.4(3.2)$ & $23.5(4.4)$ & $15.9(0.4)$ & $15.9(0.4)$ & $12.4(2.8)$ & $11.5(3.2)$ \\
\hline
\end{tabular}


Table 1 Sociodemographic, Drug Use, Mental IIIness, and Chronic Disease Characteristics by Sexual Orientation among Adults Age $\geq$ 50, United States, 2015-2017 (Continued)

\begin{tabular}{|c|c|c|c|c|c|c|c|c|}
\hline & \multicolumn{4}{|l|}{ Men } & \multicolumn{4}{|l|}{ Women } \\
\hline & $\begin{array}{l}\text { Total } \\
(n=11,876) \\
\%(\mathrm{SE})\end{array}$ & $\begin{array}{l}\text { Hetero-sexual } \\
(n=11,509) \\
\%(\mathrm{SE})\end{array}$ & $\begin{array}{l}\text { Gay } \\
(n=227) \\
\%(S E)\end{array}$ & $\begin{array}{l}\text { Bisexual } \\
(n=140) \\
\%(\mathrm{SE})\end{array}$ & $\begin{array}{l}\text { Total }(n=14,004) \\
\%(\mathrm{SE})\end{array}$ & $\begin{array}{l}\text { Hetero-sexual } \\
(n=13,708) \\
\%(\mathrm{SE})\end{array}$ & $\begin{array}{l}\text { Lesbian } \\
(n=173) \\
\%(\mathrm{SE})\end{array}$ & $\begin{array}{l}\text { Bisexual } \\
(n=123) \\
\%(\mathrm{SE})\end{array}$ \\
\hline Hepatitis B/C & $3.0(0.2)^{c}$ & $2.8(0.2)$ & $13.6(2.9)$ & $7.7(2.6)$ & $1.5(0.1)^{a}$ & $1.4(0.1)$ & $2.3(1.3)$ & $4.9(2.0)$ \\
\hline High Blood Pressure & $31.2(0.5)$ & $31.1(0.5)$ & 35.7 (3.9) & $29.6(4.8)$ & $36.3(0.5)^{a}$ & $36.4(0.5)$ & $29.5(3.7)$ & $27.2(4.1)$ \\
\hline HIV/AIDS & $0.3(0.1)^{c}$ & $0.7(0.0)$ & $12.2(2.6)$ & $1.7(0.9)$ & $0.1(0.0)$ & $0.1(0.0)$ & $0.0(0.0)$ & $0.0(0.0)$ \\
\hline Kidney Disease & $3.3(0.2)$ & $3.2(0.2)$ & $4.0(1.8)$ & $5.3(2.6)$ & $3.5(0.2)$ & $3.5(0.2)$ & $3.1(1.6)$ & $3.7(2.0)$ \\
\hline 0-1 Chronic Diseases & $74.3(0.5)^{b}$ & $74.5(0.5)$ & $63.3(3.9)$ & $74.7(4.1)$ & $73.2(0.5)$ & $73.2(0.5)$ & $72.8(4.0)$ & $74.9(4.4)$ \\
\hline Multiple Chronic Diseases & $25.7(0.5)$ & $25.5(0.5)$ & $36.7(3.9)$ & $25.3(4.1)$ & $26.8(0.5)$ & $26.8(0.5)$ & $27.2(4.0)$ & $25.1(4.4)$ \\
\hline
\end{tabular}

White and black participants were identified as non-Hispanic; SE Standard error, COPD Chronic obstructive pulmonary disease

${ }^{\text {a }}$ Significant at $P<.05$ based on Rao-Scott chi-square test

${ }^{\mathrm{b}}$ Significant at $P<.01$ based on Rao-Scott chi-square test

'Significant at $P<.001$ based on Rao-Scott chi-square test

${ }^{\mathrm{d}}$ Defined as moderate or severe mental illness based on National Survey on Drug Use and Health (NSDUH) indicator [19]

opioids in the past year, with gay men having the highest prevalence of tranquilizers misuse. Bisexual men had the highest prevalence of mental illness and gay men reported the highest prevalence of HIV diagnosis, Hepatitis $\mathrm{B}$ or $\mathrm{C}$ diagnosis, and having 2 or more chronic diseases.

In our adjusted models as shown in Table 2, gay men had a higher odds of having multiple chronic medical conditions (adjusted odds ratio $[\mathrm{aOR}]=2.18,95 \%$ confidence interval $[\mathrm{CI}]=1.48,3.21$ ) while no significant difference was found for bisexual men and lesbian/bisexual women compared to their heterosexual counterparts. For mental illness, gay men $(\mathrm{aOR}=1.79,95 \% \mathrm{CI}=1.09$, $2.93)$ and bisexual men $(\mathrm{aOR}=3.53,95 \% 2.03,6.14)$ had a higher odds of mental illness compared to heterosexual men, while bisexual women had a higher odds of mental illness $(\mathrm{aOR}=1.94,95 \% \mathrm{CI}=1.03,3.67)$ compared to heterosexual women. For drug use, bisexual women had a higher odds of reporting past-year drug use (aOR = $4.20,95 \% \mathrm{CI}=2.55,6.93)$ compared to heterosexual women, while there were no significant differences between gay and bisexual men and lesbian women and their heterosexual counterparts. With all else being equal, as shown in Table 3, compared to heterosexual men, gay men were nearly three times the odds $(\mathrm{aOR}=$ $2.95,95 \% \mathrm{CI}=1.60,5.46)$ and bisexual men were at more than double the odds $(\mathrm{aOR}=2.84,95 \% \mathrm{CI}=1.58$, 5.08) of reporting 2-3 conditions. Compared to heterosexual women, lesbian women were at more than three times the odds $(\mathrm{aOR}=3.25,95 \%=1.60,6.62)$ of reporting 2-3 conditions.

Finally, in our supplemental analyses we found that all estimates were nearly identical for gay/lesbian and bisexual individuals when including those responding "don't know" or "refuse" to the sexual orientation question. However, men and women responding "don't know" were at lower odds for having $\geq 2$ chronic medical conditions, and women who refused to respond were at lower odds for having $\geq 2$ chronic medical conditions and for having a mental illness (Supplemental Table 1). In

Table 2 Multivariable Associations between Sexual Orientation and Specific Conditions

\begin{tabular}{|c|c|c|c|}
\hline Men & $\begin{array}{l}\text { Past-Year Drug Use } \\
\text { aOR }(95 \% \mathrm{Cl})\end{array}$ & $\begin{array}{l}\geq 2 \text { Chronic Medical Conditions } \\
\text { aOR }(95 \% \mathrm{Cl})\end{array}$ & $\begin{array}{l}\text { Mental Illness } \\
\text { aOR }(95 \% \mathrm{Cl})\end{array}$ \\
\hline Heterosexual & Reference group & Reference group & Reference group \\
\hline Gay & $1.62(0.89,2.95)$ & $2.18(1.48,3.21)^{b}$ & $1.79(1.09,2.93)^{a}$ \\
\hline Bisexual & $1.88(0.99,3.56)$ & $1.07(0.66,1.72)$ & $3.53(2.03,6.14)$ \\
\hline Women & $\begin{array}{l}\text { Past-Year Drug Use } \\
\text { aOR }(95 \% \mathrm{Cl})\end{array}$ & $\begin{array}{l}\geq 2 \text { Chronic Medical Conditions } \\
\text { aOR }(95 \% \mathrm{Cl})\end{array}$ & $\begin{array}{l}\text { Mental Illness } \\
\text { aOR }(95 \% \mathrm{Cl})\end{array}$ \\
\hline Heterosexual & Reference group & Reference group & Reference group \\
\hline Lesbian & $1.70(0.97,2.98)$ & $1.05(0.71,1.55)$ & $0.87(0.44,1.73)$ \\
\hline Bisexual & $4.20(2.55,6.93)^{b}$ & $1.04(0.64,1.68)$ & $1.94(1.03,3.67)^{a}$ \\
\hline
\end{tabular}

Results were derived from six separate multivariable binary logistic regressions controlling for demographic characteristics. The comparison group in each model is no past-year drug use, not having multiple chronic diseases, and not having a mental health disorder in the past year, respectively. $a O R$ Adjusted odds ratio, $\mathrm{Cl}$ Confidence intervals, ${ }^{\text {a }}$ Significant at $P<.05,{ }^{\text {b }}$ Significant at $P<.001$ 
Table 3 Multivariable Associations between Sexual Orientation and Number of Conditions ${ }^{a}$

\begin{tabular}{|c|c|c|}
\hline Men & $\begin{array}{l}1 \text { Condition } \\
\text { aOR }(95 \% \mathrm{Cl})\end{array}$ & $\begin{array}{l}2-3 \text { Conditions } \\
\text { aOR }(95 \% \mathrm{CI})\end{array}$ \\
\hline Heterosexual & Reference group & Reference group \\
\hline Gay & $1.74(1.14,2.66)^{b}$ & $2.95(1.60,5.46)^{c}$ \\
\hline Bisexual & $1.48(0.94,2.31)$ & $2.84(1.58,5.08)^{c}$ \\
\hline Women & $\begin{array}{l}1 \text { Condition } \\
\text { aOR }(95 \% \mathrm{Cl})\end{array}$ & $\begin{array}{l}2-3 \text { Conditions } \\
\text { aOR }(95 \% \mathrm{Cl})\end{array}$ \\
\hline Heterosexual & Reference group & Reference group \\
\hline Lesbian & $1.03(0.70,1.53)$ & $1.38(0.67,2.83)$ \\
\hline Bisexual & $1.63(1.01,2.62)^{b}$ & $3.25(1.60,6.62)^{c}$ \\
\hline
\end{tabular}

Results were derived from multivariable multinomial logistic regressions controlling for demographic characteristics. The comparison group in each model is 0 conditions. aOR Adjusted odds ratio, $\mathrm{Cl}$ Confidence intervals, ${ }^{\text {a }}$ Conditions include past-year drug use, multiple chronic medical conditions, and mental illness, ${ }^{\mathrm{b}}$ Significant at $P<.05,{ }^{\mathrm{C}}$ Significant at $P<.01$

addition, men responding, "don't know" and women refusing to respond were at lower odds for having one chronic condition (Supplemental Table 2).

\section{Discussion}

To our knowledge, this is one of few studies of LGB disparities among a nationally representative sample of older adults in the US that examines multimorbidity and co-occurring conditions. We found that for both genders, middle-aged and older LGB adults had higher odds of having 2 or more co-occurring conditions (mental illness, drug use, or medical multimorbidity) compared to heterosexuals. These findings support results from other studies that identify several disparities in health and health-related risk factors among sexual minorities in the US. There are many social determinants that affect the health of sexual minorities in the US that fit with the minority stress model [22], where chronic stressors such as identity concealment, discrimination, and oppression [8], can lead to both mental illness and substance use [23], and ultimately to chronic medical disease. In addition, older LGB adults face the additional challenges of aging that increases the risks for chronic medical disease and social isolation [24]. Older LGB adults in particular often have barriers to social services and culturally competent healthcare providers [25]. Therefore older LGB adults are at elevated health risks and interventions focused on reducing the risk of poor health outcomes and a premature decline in function in this population should consider these conditions that may occur simultaneously.

An abundance of literature suggests that rates of substance use and SUDs are higher among LGBT persons compared to heterosexuals [11, 26, 27]; however, there remains very little data on prevalence among middleaged and older adults. Our study is one of few that reports drug use patterns among older LGB adults especially by gender and sexual orientation. A recent study of aggregated LGB adults age 50 and older found a higher odds of nonmedical cannabis use and prescription misuse of opioids and tranquilizers [12]. For this study, we found a much higher prevalence of nonmedical use of cannabis specifically among bisexual women. In addition, bisexual women had the highest prevalence of prescription opioid misuse compared to all other groups. Gay men meanwhile had the highest prevalence of prescription tranquilizer misuse, and bisexual men had the highest prevalence of illegal drug use. More research is needed to understand patterns of substance use among middle-aged and older LGB adults as factors for increased drug use likely differ from younger LGB adults, who may be more likely to use "club drugs" (i.e. methamphetamine, ecstasy) than older LGB individuals $[28,29]$. Several reasons may explain drug use in this population including stressors due to minority status, social isolation, as well as mental illness.

In this study, both male and female sexual minorities had a higher prevalence of mental illness compared to heterosexuals, with bisexual women having the highest prevalence. This also may be due to exposure to chronic stressors over the life course including identity concealment and the dual stigmatization of aging and belonging to a sexual minority group (and for some, also belonging to a racial/ethnic minority group). Our findings are largely consistent with several studies both in the US and in Canada that demonstrate the higher prevalence of depression, suicide attempts, and poorer mental health among older LGB compared to heterosexuals [9, 30-32]. The highest prevalence among bisexual men and women in our study may be due to lower levels of community connectedness compared to lesbian and gay men [9], which may increase isolation as one ages.

In terms of chronic disease and medical multimorbidity, our study adds new information regarding the health of middle-age and older adults among LGB adults. However, previous work on chronic disease burden in this population using national data combines adults identifying as bisexual and as gay or lesbian [3], and therefore it is difficult to make comparisons. Our study results found that gay men had the highest prevalence of multiple chronic diseases, possibly driven, in part, by also having the highest prevalence of HIV/AIDS. While older bisexual women had a lower prevalence of medical multimorbidity, they were at increased risk for having more than one co-occurring condition. Therefore, although bisexual women may appear to have a more "favorable" medical multimorbidity profile if examined in isolation, they are in fact still at high risk for poor health outcomes through multiple co-existing factors. This is consistent with previous research in younger populations, which 
has found that bisexual women were less likely to engage in health-related behaviors, report poor health status or disability, use smokeless tobacco and opioids, and not seek healthcare because of cost $[1,33,34]$. Further work is needed to better understand the health needs of older bisexual women to reduce sexual minority health disparities.

The compound multimorbidity of having more than one condition (drug use, mental illness, and/or medical multimorbidity) has implications for better understanding determinants of health for older sexual minorities and how to develop clinical interventions to address care in the setting of complexity. One method of studying such multimorbidity is a syndemic framework with a focus on how conditions are interconnected and adversely affected by behavioral and psychosocial conditions [35-37]. Syndemic theory describes how two or more conditions interact synergistically to contribute to increased vulnerability and disease burden [38], and has been used commonly to describe risks among sexual minority groups [37, 39], Our results inform the use of syndemic theory for future research in this population as older sexual minorities are at higher risk for having cooccurring conditions, which are often interrelated. Future studies could use the syndemic framework to better delineate profiles of risk by examining synergistic interactions between conditions. In addition, for all older sexual minorities, future research needs to focus on how specific conditions and co-occurring conditions predict poor health outcomes and functional decline. Lastly, future research can adopt an intersectional lens [40] to further examine subgroup differences in sexual minority disparities for multimorbidity, including racial/ethnic and nativity differences regarding co-occurring conditions among older adults by gender, which is a priority [8].

\section{Limitations}

Self-report is a limitation, as such data are susceptible to limited recall and social desirability bias. In addition, NSDUH does not ask whether participants are transgender and studies are increasingly showing health disparities among gender minorities. Another limitation of our study is that 413 participants responded "don't know" or "refuse" for the sexual orientation item. Our supplemental analyses including those responding to these categories suggest there is the possibility of bias for the outcomes of chronic medical conditions and mental illness. It is unknown which of these respondents legitimately do not know their identity, and it is unknown who actually might have identified as "other" sexuality, while others might have merely satisficed and chose such a response without thinking much about it. We highly recommend that surveys asking about sexual orientation provide an option for "other" sexuality [41].
However, the number of respondents not reporting a listed sexual orientation was low $(<1.6 \%)$ and does not appear to affect the main outcome of co-occurring conditions. Further, the sample sizes were too small to examine differences between racial/ethnic subgroups of LGB. The NSDUH also samples only the noninstitutionalized US population, and therefore does not include adults who live in long-term care settings. Finally, the survey is cross-sectional, and different participants were sampled each year; therefore, this study cannot establish causality.

\section{Conclusions}

Older sexual minorities in the US are at heightened risk for the interrelated and compound morbidity from mental illness, drug use, and chronic medical diseases. These disparities are likely due to minority stressors and discrimination along with aging and increasing social isolation. These findings indicate the need to consider how co-occurring conditions can contribute to poor health outcomes in older sexual minority populations and the need for specific interventions within this diverse group.

\section{Supplementary information}

Supplementary information accompanies this paper at https://doi.org/10. 1186/s12889-020-09210-6.

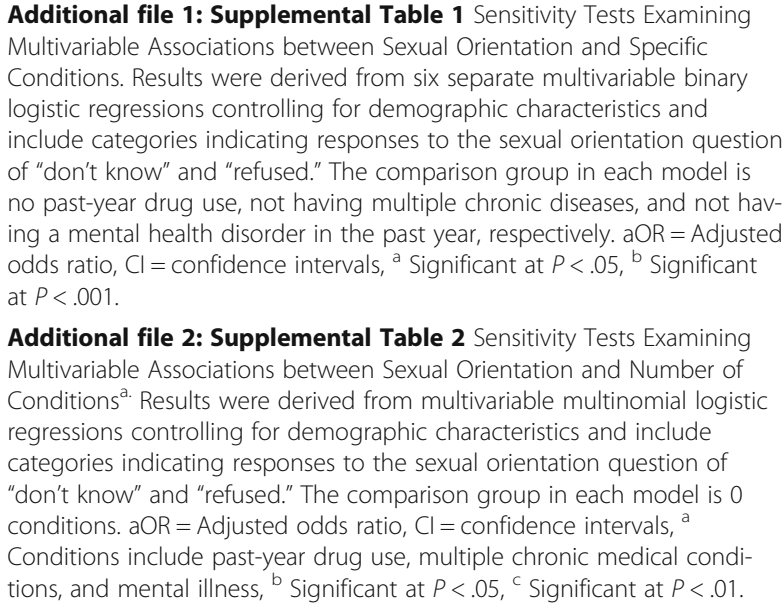

Additional file 2: Supplemental Table 2 Sensitivity Tests Examining Multivariable Associations between Sexual Orientation and Number of Conditions ${ }^{\text {a. }}$ Results were derived from multivariable multinomial logistic regressions controlling for demographic characteristics and include categories indicating responses to the sexual orientation question of "don't know" and "refused." The comparison group in each model is 0 conditions. $\mathrm{aOR}=$ Adjusted odds ratio, $\mathrm{Cl}=$ confidence intervals, ${ }^{\text {a }}$

Conditions include past-year drug use, multiple chronic medical conditions, and mental illness, ${ }^{b}$ Significant at $P<.05$, ${ }^{c}$ Significant at $P<.01$.

\section{Abbreviations}

aOR: Adjusted odds ratio; Cl: Confidence interval; GAF: Global Assessment of Functioning; LGB: Lesbian, gay, and bisexual; LGBT: Lesbian, gay, bisexual, and transgender; NHIS: National Health Interview Survey; NSDUH: National Survey on Drug Use and Health; SUD: Substance use disorder; US: United States

Acknowledgements

We thank Dr. Charles Cleland for advice on statistical analyses.

\section{Authors' contributions}

$\mathrm{BHH}$ contributed to the design and concept for this manuscript, interpreted findings, and drafted the manuscripts. DTD contributed to the design and concept for this manuscript and edited the manuscript. MAM assisted in drafting the manuscript and performed the literature review. JJP contributed 
to the design and concept for this manuscript, conducted statistical analysis, drafted the manuscript, and supervised the work. All authors have read and approved the final manuscript before submission.

\section{Funding}

This research is funded by grants from the National Institute on Drug Abuse, National Institute on Mental Health, National Institute on Minority Health and Health Disparities and the Centers for Disease Control and Prevention: Drs. Joseph Palamar and Benjamin Han were funded by grants from the National Institute on Drug Abuse: K01DA038800 (Palamar), R01DA044207 (Palamar) and K23DA043651 (Han). Dr. Dustin Duncan was funded by grants from the National Institute on Mental Health (Grant Number R01MH112406), National Institute on Minority Health and Health Disparities (Grant Number R01MD013554), and the Centers for Disease Control and Prevention (Grant Number U01PS005122). The content is solely the responsibility of the authors and does not necessarily represent the official views of the National Institutes of Health or the Centers for Disease Control and Prevention.

\section{Availability of data and materials}

The datasets used from the National Survey on Drug Use and Health for this study are publicly available at: https://www.datafiles.samhsa.gov/study-series/ national-survey-drug-use-and-health-nsduh-nid13517

\section{Ethics approval and consent to participate}

The datasets from the National Survey on Drug Use and Health are deidentified and public available, which cannot be individually identifiable and therefore not involve human subjects.

\section{Consent for publication}

Not applicable.

\section{Competing interests}

The authors declare that they have no competing interests.

\section{Author details}

'Department of Population Health, New York University School of Medicine, 550 First Avenue, New York, NY 10016, USA. ${ }^{2}$ Division of Geriatric Medicine and Palliative Care, Department of Medicine, New York University School of Medicine, 550 First Avenue, New York, NY 10016, USA. ${ }^{3}$ Department of Epidemiology, Mailman School of Public Health, Columbia University, 722 W 168th St, New York, NY 10032, USA.

\section{Received: 1 November 2019 Accepted: 5 July 2020}

\section{Published online: 04 August 2020}

\section{References}

1. Cunningham TJ, Xu F, Town M. Prevalence of five health-related behaviors for chronic disease prevention among sexual and gender minority adults - 25 U.S. states and Guam, 2016. MMWR Morb Mortal Wkly Rep. 2018;67:888-93.

2. Duncan DT, Zweig S, Hambrick HR, Palamar JJ. Sexual orientation disparities in prescription opioid misuse among U.S. adults. Am J Prev Med. 2019;56: $17-26$.

3. Fredriksen-Goldsen Kl, Kim HJ, Shui C, Bryan AEB. Chronic health conditions and key health indicators among lesbian, gay, and bisexual older US adults, 2013-2014. Am J Public Health. 2017:107:1332-8.

4. Gonzales G, Przedworski J, Henning-Smith C. Comparison of health and health risk factors between lesbian, gay, and bisexual adults and heterosexual adults in the United States: results from the National Health Interview Survey. JAMA Intern Med. 2016:176:1344-51.

5. Jackson CL, Agénor M, Johnson DA, Austin SB, Kawachi I. Sexual orientation identity disparities in health behaviors, outcomes, and services use among men and women in the United States: a cross-sectional study. BMC Public Health. 2016:16:807.

6. Ward BW, Joestl SS, Galinsky AM, Dahlhamer JM. Selected diagnosed chronic conditions by sexual orientation: a national study of US adults, 2013. Prev Chronic Dis. 2015:12:E192.

7. US Department of Health and Human Services. Healthy People 2020 objectives. http://www.healthypeople.gov/2020/topicsobjectives2020/ default.aspx. Accessed 31 Oct 2019.

8. Cahill SR. Research and policy change to improve healthcare and elder services for LGBT older adults. LGBT Health. 2017;4:381-3.
9. Yarns BC, Abrams JM, Meeks TW, Sewell DD. The mental health of older LGBT adults. Curr Psychiatry Rep. 2016;18:60.

10. Cigolle CT, Langa KM, Kabeto MU, Tian Z, Blaum CS. Geriatric conditions and disability: the health and retirement study. Ann Intern Med. 2007;147: $156-64$.

11. Capistrant BD, Nakash O. Lesbian, gay, and bisexual adults have higher prevalence of illicit opioid use than heterosexual adults: evidence from the National Survey on drug use and health, 2015-2017. LGBT Health. 2019;6:326-30.

12. Han BH, Miyoshi M, Palamar JJ. Substance use among middle-aged and older lesbian, gay, and bisexual adults in the United States, 2015 to 2017. J Gen Intern Med. 2020. https://doi.org/10.1007/s11606-020-05635-2.

13. Lunn MR, Cui W, Zack MM, Thompson WW, Blank MB, Yehia BR. Sociodemographic characteristics and health outcomes among lesbian, gay, and bisexual U.S. adults using healthy people 2020 leading health indicators. LGBT Health. 2017:4:283-94.

14. Boyd CM, Fortin M. Future of multimorbidity research: how should understanding of multimorbidity inform health system design? Public Health Rev. 2010;32:451-74.

15. Lehnert T, Heider D, Leicht $H$. Review: health care utilization and costs of elderly persons with multiple chronic conditions. Med Care Res Rev. 2011; 68:387-420.

16. Han BH, Termine DJ, Moore AA, Sherman SE, Palamar JJ. Medical multimorbidity and drug use among adults in the United States. Prev Med Rep. 2018;12:214-9.

17. Fredriksen-Goldsen Kl, Kim HJ, McKenzie GL, Krinsky L, Emlet CA. Plan of action for real-world translation of LGBTQ health and aging research. LGBT Health. 2017:4(6):384-8.

18. Center for Behavioral Health Statistics and Quality. Reports and Detailed Tables From the 2017 National Survey on Drug Use and Health (NSDUH). https://www.samhsa.gov/data/nsduh/reports-detailed-tables-2017-NSDUH.

19. Substance Abuse and Mental Health Services Administration. National Survey on drug use and health: alternative statistical models to predict mental illness. CBHSQ Methodology Report. Center for Behavioral Health Statistics and Quality. Rockville: Substance Abuse and Mental Health Services Administration; 2015.

20. Substance Abuse and Mental Health Services Administration. National Survey on Drug Use and Health: Alternative Statistical Models to Predict Mental IIIness. Rockville: Substance Abuse and Mental Health Services Administration (US); 2015. https:/www.ncbi.nlm.nih.gov/books/NBK531554. Accessed 31 Oct 2019.

21. Heeringa $S$, West BT, Berglund PA. Applied survey data analysis. Boca Raton: Chapman \& Hall/CRC; 2010.

22. Meyer $\mathbf{H}$. Prejudice, social stress, and mental health in lesbian, gay, and bisexual populations: conceptual issues and research evidence. Psychol Bull. 2003:129:674-97.

23. Mays VM, Cochran SD. Mental health correlates of perceived discrimination among lesbian, gay, and bisexual adults in the United States. Am J Public Health. 2001:91:1869-76.

24. Loucks EB, Berkman LF, Gruenewald TL, Seeman TE. Social integration is associated with fibrinogen concentration in elderly men. Psychosom Med. 2005;67:353-8.

25. Cahill S, South K, Spade J. Outing age: public policy issues affecting gay, lesbian, bisexual and transgender elders. Washington: National Gay and Lesbian Task Force; 2009. https://www.lgbtagingcenter.org/resources/pdfs/ OutingAge2010.pdf. Accessed 31 Oct 2019.

26. McCabe SE, Hughes TL, Bostwick WB, West BT, Boyd CJ. Sexual orientation, substance use behaviors and substance dependence in the United States. Addiction. 2009:104:1333-45.

27. Drabble L, Midanik LT, Trocki K. Reports of alcohol consumption and alcohol-related problems among homosexual, bisexual and heterosexual respondents: results from the 2000 National Alcohol Survey. J Stud Alcohol. 2005;66:111-20

28. Halkitis PN, Palamar JJ, Mukherjee PP. Poly-club-drug use among gay and bisexual men: a longitudinal analysis. Drug Alcohol Depend. 2007;89:153-60.66.

29. Parsons JT, Kelly BC, Wells BE. Differences in club drug use between heterosexual and lesbian/bisexual females. Addict Behav. 2006;31:2344-9.

30. Sivakumaran G, Margolis R. Self-rated health by sexual orientation among middle-aged and older adults in Canada. J Gerontol B Psychol Sci Soc Sci. 2019;gbz067.

31. D'Augelli A, Grossman A. Disclosure of sexual orientation, victimization, and mental health among lesbian, gay, and bisexual older adults. J Interpers Violence. 2001;16:1008-27.58. 
32. Nuttbrock L, Hwahng S, Bockting W, et al. Psychiatric impact of genderrelated abuse across the life course of male-to-female transgender populations. J Sex Res. 2010;47:12.

33. Dragon CN, Laffan AM, Erdem E, et al. Health indicators for older sexual minorities: National Health Interview Survey, 2013-2014. LGBT Health. 2017;4: 398-403.

34. Blosnich JR, Farmer GW, Lee JG, Silenzio VM, Bowen DJ. Health inequalities among sexual minority adults: evidence from ten U.S. states, 2010. Am J Prev Med. 2014;46:337-49.

35. Bhugra D, Ventriglio A. Mind and body: physical health needs of individuals with mental illness in the 21st century. World Psychiatry. 2017;16:47-8.

36. Singer MC, Erickson PI, Badiane L, Diaz R, Ortiz D, Abraham T, Nicolaysen AM. Syndemics, sex and the city: understanding sexually transmitted diseases in social and cultural context. Soc Sci Med. 2006;63:2010-21.

37. Stall R, Mills TC, Williamson J, et al. Association of co-occurring psychosocial health problems and increased vulnerability to HIV/AIDS among urban men who have sex with men. Am J Public Health. 2003:93:939-42.

38. Singer M, Clair S. Syndemics and public health: reconceptualizing disease in bio-social context. Med Anthropol Q. 2003;17:423-41.

39. Dyer TP, Shoptaw S, Guadamuz TE, et al. Application of syndemic theory to black men who have sex with men in the multicenter AIDS cohort study. J Urban Health. 2012;89:697-708.

40. Bowleg $\mathrm{L}$. The problem with the phrase women and minorities: Intersectionality - an important theoretical framework for public health. Am J Public Health. 2012;102:1267-73.

41. Griffin M, Callander D, Duncan DT, Palamar JJ. Differential risk for drug use by sexual minority status among electronic dance music party attendees in New York City. Subst Use Misuse. 2020;55:230-40.

\section{Publisher's Note}

Springer Nature remains neutral with regard to jurisdictional claims in published maps and institutional affiliations.

Ready to submit your research? Choose BMC and benefit from:

- fast, convenient online submission

- thorough peer review by experienced researchers in your field

- rapid publication on acceptance

- support for research data, including large and complex data types

- gold Open Access which fosters wider collaboration and increased citations

- maximum visibility for your research: over $100 \mathrm{M}$ website views per year

At $\mathrm{BMC}$, research is always in progress.

Learn more biomedcentral.com/submissions 